\title{
Dukungan Pemenuhan Activity Daily Living (ADL) Pada Lanjut Usia di Balai Sosial Lanjut Usia Meci Angi
}

\author{
$\operatorname{Muhtar}^{1(\mathrm{CA})}$, Aniharyati ${ }^{2}$ \\ ${ }^{1(\mathrm{CA})}$ Jurusan Keperawatan, Poltekkes Kemenkes Mataram, Indonesia; email: muhtarbima @ gmail.com \\ ${ }^{2}$ Jurusan Keperawatan, Poltekkes Kemenkes Mataram, Indonesia
}

\begin{abstract}
This increase in the number of elderly has the potential to cause several key problems such as increasing the burden on families, communities, and government, especially relating to the need for special services, the provision and expansion of employment, social psychological consultative services, socio-economic assistance, efforts to preserve social culture, and health services. This study aims to explore the relationship between service provider support and ADL fulfillment in the elderly. using descriptive analytic design with cross sectional design, sampling with a purporsive sampling method with a sample of 50 respondents, data analysis using the non-parametric test Chi-Square with the help of a computer program. The results of the bivariate analysis using the Chi-Square test obtained $X^{2}$ value of 20,261 with a $\mathrm{p}$ value of 0.001 which means there is a relationship between service provider support and ADL fulfillment in the elderly at Meci Angi Elderly Social Center
\end{abstract}

\section{Keywords: Activity Daily Living; Elderly}

\begin{abstract}
ABSTRAK
Peningkatan jumlah lanjut usia ini berpotensi menimbulkan beberapa masalah pokok seperti meningkatnya beban keluarga, masyarakat, dan pemerintah, khususnya berhubungan dengan kebutuhan layanan khusus, penyediaan dan perluasan lapangan kerja, pelayanan konsultatif sosial psikologis, bantuan sosial ekonomi, upaya pelestarian sosial budaya, dan pelayanan kesehatan. Penelitian ini bertujuan untuk menggali hubungan dukungan pemberi pelayanan dengan pemenuhan ADL pada lansia. menggunakan desain deskriptif analitik dengan rancangan cross sectional, pengambilan sampel dengan metode purporsive sampling dengan jumlah sampel 50 responden, analisis data menggunakan uji nonparametrik Chi-Square dengan bantuan program komputer. Hasil analisis bivariat menggunakan uji Chi-Square didapatkan nilai $\mathrm{X}^{2}$ sebesar 20,261 dengan nilai $p$ value sebesar 0,001 yang berarti ada hubungan antara dukungan pemberi pelayanan dengan pemenuhan ADL pada lansia di Balai Sosial Lanjut Usia Meci Angi
\end{abstract}

\section{Kata Kunci : Activity Daily Living; Lanjut Usia}

\section{PENDAHULUAN}

Jumlah penduduk lanjut usia terus meningkat baik di Indonesia maupun di dunia dan membawa serta berbagai permasalahan yang harus diantisipasi dan dicarikan jalan keluarnya (Sulastri \& Humaedi, 2017). Peningkatan jumlah lanjut usia ini berpotensi menimbulkan beberapa masalah pokok seperti meningkatnya beban keluarga, masyarakat, dan pemerintah, khususnya berhubungan dengan kebutuhan layanan khusus, penyediaan dan perluasan lapangan kerja, pelayanan konsultatif sosial psikologis, bantuan sosial ekonomi, upaya pelestarian sosial budaya, dan pelayanan kesehatan (Insiyah \& Rini Tri Hastuti, 2014) 
Pergeseran nilai sosial budaya yang terjadi di masyarakat kita saat ini yaitu dengan adanya perubahan sikap dan pandangan mereka yang cenderung negatif terhadap lansia, serta dengan tatanan masyarakat yang individualistik atau masyarakat yang lebih mementingkan kepentingan pribadi tanpa memperhatikan lingkungan di sekitarnya membuat lansia semakin kurang diperhatikan (Azizah \& Rahayu, 2016). Seorang lansia seharusnya mendapatkan perhatian dan penanganan yang lebih serius lagi karena seseorang yang memasuki masa lansia mempunyai banyak keluhan baik secara fisik, psikis, sosial dan spiritual yang akan mempengaruhi status kesehatan mereka, oleh karena itu untuk mencegah atau memiminimalkan masalah-masalah diatas maka dukungan caregiver (pemberi pelayanan) sangat dibutuhkan (Yuniati, 2017).

Pemberi pelayanan pada lansia, yaitu orang yang dekat dengan lansia dan mengerti tentang hal-hal yang berhubungan dengan lansia tersebut, baik tentang perubahan fisik, psikis, dan sosial. Orang-orang tersebut seperti petugas panti, pekerja sosial, dan yang terutama adalah petugas kesehatan (perawat dan dokter). Seorang pemberi pelayanan wajib mengetahui penyebab dan proses kemunduran fisik yang dialami lansia sehingga ia sudah dapat mengantisipasi pemberian dukungan apa yang akan diberikan kepada lansia agar kebutuhan-kebutuhan Activity Daily Living (ADL) lansia tetap terpenuhi baik dengan bantuan sebagian maupun dengan bantuan penuh (Taviyanda \& Aris Siswanto, 2016). Adapun kebutuhan ADL lansia meliputi bathing, dressing, toiletting, transfering, kontinence, dan feedding.

Dengan adanya dukungan dalam pemenuhan ADL pada lansia tersebut bukan berarti bahwa setelah memasuki masa lansia seseorang hanya tinggal duduk, diam, tenang dan berdiam diri saja. Dalam rangka membantu agar lansia tetap beraktivitas maka dibutuhkan dukungan dari pemberi pelayanan (caregiver). Masalah fisik atau yang berhubungan dengan ADL pada lansia merupakan faktor yang tidak kalah penting dari masalah-masalah lain yang dihadapi lansia, bahkan masalah pemenuhan ADL dianggap lebih menonjol bila dibanding dengan masalah lainnya (Baroroh \& Irafayani, 2015). Dari informasi yang diperoleh dari Balai Sosial Lanjut Usia Meci Angi bahwa seluruh pengasuh di panti tersebut tidak memiliki kualifikasi pendidikan yang memadai tentang pemberian perawatan yang mendukung para lansia agar kebutuhan ADL dari para lansia tetap terpenuhi. Penelitian ini bertujuan untuk menggali hubungan dukungan pemberi pelayanan dengan pemenuhan ADL pada lansia.

\section{METODE}

Desain penelitian yang digunakan adalah deskriptif analitik dengan rancangan cross sectional. Pengambilan sampel dengan metode Purporsive sampling dengan jumlah sampel 50 responden, pada responden yang memenuhi kriteria inklusi: Lansia yang sehat dan tidak mengalami gangguan jiwa, bisa mendengar dengan baik, dapat berkomunikasi verbal, dan Lansia yang tinggal dipanti minimal dua tahun. Kuesioner pada penelitian ini terdiri dari dua bagian yaitu bagian (A) dukungan pemberi pelayanan dan bagian (B) pernyataan mengenai pemenuhan ADL lansia yang terdiri atas Bathing, dressing, toileting, transfering, dan feeding. Analisis data menggunakan uji nonparametrik Chi-Square dengan bantuan program komputer. 


\section{HASIL DAN PEMBAHASAN}

\section{Karakteristik Responden}

Tabel 1. Karakteristik responden di Balai Sosial Lanjut Usia Meci Angi, Oktober 2018, n=50

\begin{tabular}{llll}
\hline No & \multicolumn{1}{c}{ Karakteristik } & Frekuensi (n) & Persentase $(\%)$ \\
\hline 1. & Jenis Kelamin & & \\
& Laki-Laki & 34 & 68 \\
& Perempuan & 16 & 32 \\
\hline 2. & Umur & & \\
& $<60$ Tahun & 7 & 14 \\
& $60-74$ Tahun & 30 & 60 \\
& $>75$ Tahun & 13 & 26 \\
\hline
\end{tabular}

Table 1 menunjukan jenis kelamin responden terbanyak laki-laki (68\%) dengan kelompok umur yang terbanyak pada usia 60-74 tahun yaitu sebanyak $60 \%$.

\section{Dukungan Pemenuhan ADL}

Tabel 2. Distribusi Responden Berdasarkan Dukungan Pemenuhan ADL di Balai Sosial Lanjut Usia Meci Angi, Oktober 2018, $\mathrm{n}=50$

\begin{tabular}{clcc}
\hline No & \multicolumn{1}{c}{ Dukungan Pemenuhan ADL } & Frekuensi (n) & Persentase (\%) \\
\hline 1. & Ada dukungan & 36 & 72 \\
2. & Tidak ada dukungan & 14 & 28 \\
\hline
\end{tabular}

Tabel 2 menunjukkan bahwa 72\% mendapatkan dukungan pemberi pelayanan dalam pemenuhan ADL. Dukungan dari pemberi pelayanan efektif karena diberikan pada saat yang tepat dan sesuai dengan kebutuhan individu dalam bentuk bantuan pemenuhan kebutuhan dalam kehidupan. Hal ini akan terwujud apabila semua faktor mendukung diantaranya adanya waktu dari pemberi pelayanan dan fasilitas serta dukungan tersebut memperoleh feed back yang positif (Prabasari, Juwita, \& Maryuti, 2017).

Dengan adanya kedekatan antara lansia dengan pemberi pelayanan di panti dimungkinkan pendampingan yang efektif terhadap lansia. Hal ini sesuai dengan konsep teori bahwa seseorang akan lebih mudah mendapatkan dukungan dari orang-orang yang berada dekat dengannya (Baroroh \& Irafayani, 2015). Hal ini ditunjukkan bahwa 63,3\% memberikan jawaban bahwa mereka merasa menjadi anggota keluarga dalam panti tersebut.

Dukungan dari pemberi pelayanan merupakan ungkapan hormat, dorongan untuk maju, bimbingan dan menengahi pemecahan masalah. Lansia yang mendapat dukungan yang tinggi dari pengasuh akan memandang positif dalam hidupnya, mempunyai self esstem yang tinggi. Hal ini menyebabkan lansia tidak merasa sungkan untuk meminta pertolongan (Baroroh \& Irafayani, 2015). 


\section{Kemampuan Pemenuhan ADL}

Tabel 3. Distribusi Responden Berdasarkan Kemampuan Pemenuhan ADL di Balai Sosial Lanjut Usia Meci Angi, Oktober 2018, n=50

\begin{tabular}{clcc}
\hline No & Kemampuan Pemenuhan ADL & Frekuensi (n) & Persentase (\%) \\
\hline 1. & ADL terpenuhi & 39 & 78 \\
2. & ADL tidak terpenuhi & 11 & 22 \\
\hline
\end{tabular}

Tabel 3 menunjukkan bahwa $78 \%$ responden memiliki kemampaun dalam memenuhi kebutuhan ADL. Jika proses menua mulai berlangsung, di dalam tubuh juga mulai terjadi perubahan - perubahan struktural yang merupakan proses degeneratif. Sel-sel menjadi mengecil atau komposisi sel pembentukan jaringan ikat baru menggantikan sel-sel yang hilang sebagai akibatnya akan timbul kemunduran fungsi organ-organ tubuh. Proses menua adalah proses alami yang disertai adanya penurunan kondisi fisik, psikologis maupun sosial yang saling berinteraksi satu sama lain (Darmojo \& Martoyo, 2004).

Secara umum kondisi fisik seseorang yang sudah memasuki masa lanjut usia mengalami penurunan secara berlipat ganda. Setelah memasuki masa lanjut usia mulai dihinggapi adanya kondisi fisik yang patologis berganda, misalnya tenaga berkurang, energi menurun, kulit makin keriput, gigi makin rontok, tulang makin rapuh. Keadaan ini dapat menimbulkan gangguan fungsi fisik, psikologis maupun sosial (Wahyudi, 2000). Pada masa tua pandangan mulai kabur, pendengaran berkurang dan jaringan otot menyusut. Hal tersebut menyebabkan menurunnya kemampuan koordinasi dari anggota gerak. Teori-teori yang berhubungan dengan penuaan menyebutkan bahwa pada suatu waktu semua lansia akan mengalami kemunduran fungsi gerak namun batas waktu tersebut berbeda pada tiap lansia. Pandangan yang menyebutkan bahwa usia 60 tahun merupakan usia yang tidak produktif juga tidak dapat diterima begitu saja.

\section{Hubungan dukungan dengan kemampuan pemenuhan $A D L$}

Tabel 4: tabulasi silang antara dukungan pelayanan dengan pemenuhan ADL di Balai Sosial Lanjut Usia Meci Angi, Oktober 2018, n=50

\begin{tabular}{|c|c|c|c|c|}
\hline \multirow{5}{*}{$\begin{array}{l}\text { Dukungan Pemenuhan } \\
\text { ADL }\end{array}$} & & \multicolumn{2}{|c|}{ Kemampuan Pemenuhan ADL } & \multirow{2}{*}{ Total } \\
\hline & & Terpenuhi & Tidak terpenuhi & \\
\hline & \multirow{2}{*}{ Ada dukungan } & 34 & 2 & 36 \\
\hline & & $94,4 \%$ & $5,6 \%$ & $100 \%$ \\
\hline & Tidak ada & 5 & 9 & 14 \\
\hline & dukungan & $35,7 \%$ & $64,3 \%$ & $100 \%$ \\
\hline
\end{tabular}

Tabel 4 menunjukkan bahwa $68 \%$ responden ada dukungan pemberi pelayanana dalam pemenuhan ADL dan kebutuhan ADL-nya terpenuhi. Berdasarkan hasil analisis bivariat menggunakan uji Chi-Square didapatkan nilai $\mathrm{X}^{2}$ sebesar 20,261 dengan nilai $p$ value sebesar 0,001 yang berarti ada 
hubungan antara dukungan pemberi pelayanan dengan pemenuhan ADL pada lansia di Balai Sosial Lanjut Usia Meci Angi. Lansia yang memperoleh dukungan sosial, fasilitas, serta bantuan langsung dalam melakukan aktifitas fisik akan dapat melakukan aktivitas yang biasa dilakukan sehari-hari. Terutama jika dukungan tersebut datang dari pemberi pelayanan (pengasuh) maka lansia akan merasakan keakraban, dan merasa diterima sehingga menumbuhkan sikap positif dalam menghadapi kehidupan (Darmojo \& Martoyo, 2004)

Dukungan yang diterima bergantung pada faktor-faktor seperti status perkawinan, usia dan kemampuan menggerakkan dukungan. Dukungan seperti keberadaan, kesediaan, kepedulian dari orangorang yang dapat diandalkan, menghargai dan menyayangi membuat lansia merasakan dukungan secara langsung sehingga lansia tidak merasakan sungkan untuk meminta pertolongan. Adanya kenyamanan, perhatian, penghargaan atau pertolongan dari orang lain dengan sikap menerima kondisinya membuat dukungan tersebut dirasakan berarti bagi lansia. Namun perlu diketahui seberapa banyak sumber dukungan sosial ini efektif bagi individu yang memerlukan. Sumber dukungan sosial merupakan aspek penting untuk diketahui (Smeltzer, Bare, Hinkle, \& Cheever, 2010).

Ada dua sumber dukungan yaitu sumber artificial dan sumber natural. Dukungan yang natural diterima seseorang melalui interaksi sosial dalam kehidupannya secara spontan dengan orang-orang yang berada disekitarnya, misalnya anggota keluarga atau pengasuh di panti wredha. Dukungan ini bersifat non formal. Sementara itu yang dimaksud dengan dukungan sosial artificial adalah dukungan sosial yang dirancang ke dalam kebutuhan primer seseorang, misalnya dukungan sosial akibat bencana alam melaui berbagai sumbangan sosial (Wahyudi, 2000).

Lansia yang memiliki dukungan dari pemberi pelayanan baik dari pengasuh maupun mahasiswa selama melakukan praktek belajar lapangan keperawatan gerontik serta kelayan lain di panti dapat menyelesaikan aktivitas keseharian dengan baik. Lansia mendapatkan bantuan ketika mau ke kamar mandi, mau ke toilet, atau ke dapur untuk minum atau mencuci pakaian. Dukungan yang diberikan tersebut sangat berharga bagi lansia sehingga meningkatkan perasaan positif dan merasa bahwa mereka tidak diabaikan dimasa tua (Darmojo \& Martoyo, 2004).

\section{KESIMPULAN}

Ada hubungan dukungan pemberi pelayanan dengan kemampuan pemenuhan ADL pada lansia di Balai Sosial Lanjut Usia Meci Angi. Selanjutnya disarankan bagi institusi panti agar lebih meningkatkan pelayanan kepada lansia yang tinggal di panti. Juga dapat lebih ditingkatkan pemberdayaan terhadap sesama lansia yang masih memiliki kemampuan untuk mengambil peran sebagai pemberi pelayanan sehingga meningkatkan interaksi dan rasa kekeluargaan diantara sesama penghuni panti. Dan diharapkan agar perawat dapat mensosialisasikan hal ini kepada pekerja sosial yang melaksanakan pendampingan lansia (pengasuhan) sehingga kebutuhan lansia dapat terpenuhi.

\section{DAFTAR PUSTAKA}

Azizah, A., \& Rahayu, S. (2016). Hubungan Self-esteem Dengan Tingkat Kecenderungan Kesepian Pada Lansia. Jurnal Penelitian Psikologi, 7(2), 40-58. 
Baroroh, D. B., \& Irafayani, N. (2015). Peran keluarga sebagai Care Giver Terhadap Pengelolaan Aktivitas Pada Lansia Dengan Pendekatan NIC dan NOC. Jurnal Keperawatan, 3(2), 141-151.

Darmojo RB, Martoyo HH (2004) Buku ajar geriatri (ilmu kesehatan usia lanjut). Jakarta: Balai Penerbit Fakultas Kedokteran Universitas Indonesia.

Insiyah, \& Rini Tri Hastuti. (2014). Pengaruh Terapi Penyelesaian Masalah (Problem Solving Therapy) Terhadap Penurunan Distress Psikologik Pada Caregiver Lansia Di Rt 03 Rw 04 Mojosongo, Jebres, Surakarta. Jurnal Terpadu Ilmu Kesehatan, 3(2), 106-214.

Prabasari, N. A., Juwita, L., \& Maryuti, I. A. (2017). PENGALAMAN KELUARGA DALAM MERAWAT LANSIA DI RUMAH (STUDI FENOMENOLOGI). Jurnal Ners Lentera, 5(1), 5668.

Smeltzer, S. C., Bare, B. G., Hinkle, J. L., \& Cheever, K. H. (2010). Brunner \& Suddarth's textbook of medical-surgical nursing (12th ed.). Philadelphia: Lippincott Williams \& Wilkins.

Sulastri, S., \& Humaedi, S. (2017). Pelayanan Lanjut Usia Terlantar Dalam Panti. Prosiding Penelitian Dan Pengabdian Kepada Masyarakat, 4(1), 155. https://doi.org/10.24198/jppm.v4i1.14225

Taviyanda, D., \& Aris Siswanto. (2016). Penerapan Fungsi Afektif Keluarga Pada Lansia Dalam Pemenuhan Activity Daily Living Application. Jurnal Penelitian Keperawatan, 2(2), 144-149. https://doi.org/10.1017/CBO9781107415324.004

Wahyudi, Nugroho (2000) Keperawatan Geriatrik. Jakarta: Penerbit Buku Kedokteran EGC

Yuniati, F. (2017). Pengalaman Caregiver dalam Merawat Lanjut Usia dengan Penurunan Daya Ingat. Jurnal Bahana Kesehatan Masarakat, 1(1), 27-42. 